\title{
Bibliografia de João Braz de Oliveira Arruda *.
}

As referências numéricas são do fichário da Biblioteca da Faculdade de Direito da USP.

\section{Obras}

1. Ação de enriquecimento - Secção de obras de "O Estado" - São Paulo 1919 - $1 .^{\circ}$ volume - S5-26-14.

2. Advogados em inventarios e partilhas - O codigo de processo em elaboração - E. G. da "Revista dos Tribunaes" — São Paulo - 1936 - 1 folheto - N5-26-27.

3. Arresto - Tribunal de Justiça de São Paulo - Agravo numero 3.732 - Ribeirão Preto, (memorial) - Typ. Espindola, Siqueira Cia. - S. Paulo - 1904.

4. Caução de letra - Comarca de Rib. Preto - Ação decendiaria (razões finaes) Typ. Carlos Gerke Cia., São Paulo 1898 - 1 folheto - S5-23-20.

5. Competencia do juiz para interpretar clausula testamentária, Tribunal de Justiça de São Paulo - Apelação numero 5.077, Ribeirão Preto, (memorial) - Esc. Prof. Salesianas - São Paulo - 1907 - Q14-26-2.

6. Competencia da justiça federal, Supremo Tribunal Federa] - Embargos - Recurso extraordinário numero 1.032 - (memorial) - Seção de obras de "O Estado" - São Paulo 1918 - 1 folheto - S1-25-20.

7. Conta-Corrente com garantia hypotecaria - Tribunal de Jus. tiça de São Paulo - Embargos - Ribeirão Preto -- (arrazoado) - Typ. da Companhia Industrial - São Paulo - 1900 - 1 folheto - S5-23-23.

8. Cumplicidade de Roubo - Discurso proferido em defesa de José Rodrigues, Adolpho Solingre e outros - Tribunal de Jury de Campinas - Typ. de Carlos Gerke Cia. — São Paulo - 1898 - 1 folheto - S5-23-20. 
9. Da Responsabilidade dos administradores das sociedades año. nimas - Augusto Siqueira \& Comp. - São Paulo - 1917 1 folheto - S14-25-21.

10. Decreto numero 2.044 de 31 de Dezembro de 1908 - annotado - Escolas Prof. Salesianas - São Paulo - 1914-1915 - 2 volumes - R12-25-35 e 36 .

11. Defesa na Ação Cambial - Parte Pratica - Typ. Siqueira, Nagel Cia. — São Paulo - 1914 - 1 volume - S3-23-7.

12. Defesa Crime - Discurso proferido a 7 de maio de 1912, perante as Câmaras reunidas do Tribunal de Justiça de São Paulo, em defesa do Dr. Geraldo Leite de Magalhães Gomes, Juiz de Direito de Bananal - Estabelecimento Gráfico Universal - São Paulo - 1912 - 1 volume - P9-12-21.

13. Defesa do juiz de direito de Baurú, dr. Rodrigo Romeiro no processo movido contra o mesmo pela Procuradoria Geral do Estado perante o Egrégio Tribunal de Justiça - sem mencionar editor e lugar — sem data - 1 folheto - S13-11-46.

14. Defloramento - Elementos do delito - Seducção - Tribunal de Justiça de São Paulo - Recurso Crime - (memorial) Typ. de Espindola, Siqueira \& Cia., - São Paulo, - 1904 1 folheto - S3-23-7.

15. Defloramento - Seducção - Comarca de Ribeirão Preto (defesa crime) - Typ. da Casa Beschizza - Ribeirão Preto - 1904 - 1 folheto - S3-23-7.

16. Demarcação - Vistoria - (impugnação de embargos) - sem mencionar editor - São Paulo - 1916 - 1 folheto - S3-23-7.

17 Desapropriação por necessidade e por utilidade publica E materia de direito publico - Indenização prévia - Tribu. nal de Justiça de São Paulo - Embargos n. 10.599 - (razões) sem mencionar editor - Rio de Janeiro, 1921 - Com parece. res de Ruy Barbosa - Clovis Bevilacqua - Lacerda de Almeida - Eduardo Espinola - Alfredo Bernardes da Silva Carlos Maximiliano - Araujo de Castro - Paulo de Lacerda e Martinho Garcez - 1 volume - S3-23-7.

18. A desaproprią̧ão da São Paulo Northern - Tribunal de Justiça de São Paulo - Embargos n. 10.599 - (razões da em. bargante - São Paulo Northern Railroad Co.) Com parece. ceres de Ruy Barbosa - Alfredo Bernardes - Eduardo Espi. nola - Clovis Bevilacqua - Lacerda de Almeida - Araujo de Castro - Carlos Maximiliano - Paulo de Lacerda e Martinho Garcez - Rio de Janeiro - 1921 - 1 folheto S11-21-1. 
19. O Direito romano e o seu método - Typ. Andrade Mello - São Paulo - 1903 - artigo publicado na Gazeta Juridica - volume XXXIII - n. $1-1$ folheto - P11-13-17.

20. Do Casamento - Typ. C. Manderbach \& Co. - São Paulo 1911 - 1 vol. - N10-14-17.

21. Do Regimen democratico - São Paulo Editora Limitada São Paulo - 1 vol. - Q8-25-25.

22. Effeitos da apellação - Tribunal de Justiça de São Paulo Comarca de Rib. Preto - Aggravo de instrumento - Ação decendiaria - (memorial) - Typ. Casa Beschizza - Ribeirão Preto - $1905-1$ folheto - S5-23-4.

23. Estudo juridico-philosophico - Typ. Monitor Paulista - Bananal - Est. de S. Paulo - 1881 - publicado quando quintanista da Faculdade de Direito - 1 vol. - S10-14-29.

24. Executivo fiscal pendente de julgamento - Interpretação do artigo 185 da Constituição Federal: a proibição constitucional de não poder o imposto ou taxa ser elevado além de $20 \%$ se aplica aos casos anteriores á promulgação da Constituição Federal desde que a cobrança judicial não tenha sido iniciada - Executivo fiscal pendente de julgamento - Juizo de direito da 9. ${ }^{\mathrm{a}}$ vara civel da capital - Empreza Grafica da "Revista dos Tribunaes" - São Paulo - $1935-1$ folheto - S11-23-35.

25. Fallencia - Excussão de objecto hypothecado - Pagamento das custas da excussão e do processo falimentar - Tribunal de Justiça de São Paulo - Carta testemunhavel numero 8.137 - Capital - (memorial) - Casa Espindola - São Paulo 1916 - 1 folheto - S3-23-7.

26. Falencia fraudulenta - Juizo de Direito de Rib. Preto - (memorial) - Duprat Cia. - editores - São Paulo 1905 - 1 folheto - S5-23-4.

27 Fideicomisso - Tribunal de Justiça de São Paulo - Apelação civel numero 6.502 - Capital - (memorial) sem mencionar editor - São Paulo - 1911 - 1 folheto - S3-23-7.

28. Filosofia do Direito - 3. a edição - São Paulo - Faculdade de Direito - 1942 - G1-12-2 e 3.

29. Honorarios de advogado - Acção ordinaria civel - Comarca de Ribeirão Preto - (arrazoado) - Typ. Carlos Gerke São Paulo - 1898 - 1 folheto - S1-23-13.

30. Honorários de advogado - Nulidade por falta de citação do marido de uma menor que foi citada como menor pubere Comarca de Ribeirão Preto - Ação ordinaria civel - (alega- 
ções) - Typ. Carlos Gerke - São Paulo - 1898 - 1 folheto - S5-23-20.

31. Honorarios medicos - Tribunal de Justiça de São Paulo 1894 - 1 folheto - S5-23-22.

32. Hypoteca - Escritura passada por escrivão incompetente Tribunal de Justiça de São Paulo - Apelação civel numero 4.005 - Ribeirão Preto - (memorial) - Typ. Selesiana São Paulo $-1904-1$ folheto - S3-23-7.

33. Imissão de posse contra o executado em arrematação, negada por ter sido julgada absoleta pelo despacho agravado - Tribunal de Justiça de São Paulo - Agravo - (memorial) Casa Graphica - São Paulo - 1914 - 1 folheto - S3-23-7.

34. Indice das leis mais notaveis do Estado de São Paulo até dezembro de 1929 - Empresa Grafica "Revista dos Tribunaes" São Paulo - 1931 - 1 folheto - S7-24-38.

35. Injurias impressas - Tribunal de Justiça de São Paulo Apelação crime - Comarca de Rib. Preto - (memorial) Escola Typografica Salesiana - São Paulo - 1904 - 1 folheto - S3-23-7.

36. Inventario - Partilha - Tribunal de Justiça de São Paulo Apelação civel numero 6.673 - Capital - (memorial) - Typ. de Rotschild Cia. - 1911 - 1 folheto S3-23-7.

37. Letra de cambio sancionada em garantia de conta corrente - Efeitos do endosso - (Razões finaes) - Sem mencionar editor - Ribeirão Preto - 1898 - 1 volume - S3-23-7.

38. Letra de cambio sem menção de causa - Quando o titulo não vencido dá lugar a arresto - Deposito em pagamento Tribunal de Justiça de São Paulo - Apelação numero 4.928 - capital - (memorial) - Escolas Profissionaes Salesianas - São Paulo - 1907 - 1 folheto - S5-23-4.

39. Mandato - Renuncia do advogado mandatario por não ter o mandante recursos precisos para cumprir o mandato - Tribunal de Justiça de São Paulo - Agravo de instrumento numero 2.520 - Ribeirão Preto - (alegaçōes) - Typ. da Cia. Industrial — São Paulo - 1900 - 1 folheto - Q16-26-11.

40. Meios de reconhecimento da filiação natural - Estado e prova de estado - Confissão - Tribunal de Justiça de São Paulo - Apelação numero 3.950 - Ribeirão Preto - (memorial) - Typ. Espindola - Siqueira Cia. - São Paulo - 1904 1 folheto - S3-23-7.

41. O Moloch moderno - Estudo da crise do Estado moderno São Paulo Editora Ltda - São Paulo - 1932 - 1 volume Q6-26-29. 
42. Móra - Tribunal de Justiça de São Paulo - Agravo numero 2.575 - Ribeirão Preto - (memorial e contra-minuta) - Typ. da Companhia Industrial - São Paulo - 1901 - 1 folheto - S5-23-23.

43. Opiniões de jurisconsultos nacionaes, a respeito das obras publicadas pelo Dr. Spencer Vampré - Livraria Magalhães São Paulo - 1917 - 1 folheto - S12-25-6.

44. Patrio Poder - Siqueira, Nagel Cia - São Paulo - 1912 -1 folheto - T4-13-19.

45. Filosofia do Direito - Publ. da Fac. de Direito da Univ. São Paulo - Empresa Grafica "Rev. dos Tribunaes" - 1942 3. ${ }^{\mathrm{a}}$ edição - 2 volumes - S12-13-5 e 6 .

46. Filosofia do direito - Typ. Piratininga - São Paulo - 1915 - Preleções taquigrafadas por Manuel Alves de Souza - $2^{\text {a }}$ edição -1 volume - R5-13-23.

47 Preleções de Filosofia do Direito - sem mencionar editora - São Paulo - 1908 - 1 volume P4-15-29.

48. Prevaricação - artigo 207 - do codigo penal - Discurso proferido no Tribunal de Justiça de São Paulo, em favor do juiz de direito do Bananal - (defesa crime) - Estabelecimento Grafico Universal — São Paulo - 1912 - 1 folheto - Q16-26-11.

49. Programma de ensino do curso de philosophia do direito da 1. ${ }^{a}$ cadeira do $1 .^{\circ}$ ano, da Faculdade de Direito de São Paulo Typ. Siqueira - São Paulo - 1930 - 1 volume - S2-27-33.

50. Proletariado intelectual - O chômage intelectual - Memorias apresentadas ao Conselho da Ordem dos Advogados - Empresa Grafica da "Revista dos Tribunaes" - São Paulo — 1935 - 1 folheto - S11-23-23.

51. Quarenta annos de vida forense - Escolas Profissionaes Salesianas - S. Paulo - 1921 - 1 volume - Q10-25-27.

52. A questão dos telefones automáticos - agravo n. 8.184 memorial explicativo do pleito com todas as vicissitudes sem indicações - 1 volume - de folhetos - P9-12-2.

53. Questões de dominio - Vicios de escrituras - Tribunal de Justiça de São Paulo - Embargos numero 13.021 - Rio Preto - (allegaçōes) - Secção de obras do "O Estado" São Paulo, - 1927 - 1 volume - S14-20-7.

54. Respeito á Constituição - Empr. Graf. Rev. Tribunais - S. Paulo - 1935 - 1 folheto - O11-15-19.

.55. Retenção de autos - Trib. Justiça de S. Paulo - Agravo de petição - Capital - (minuta) - Typ. Maré, Monti \& Co. São Paulo - 1911 - 1 folheto - S3-23-7. 
56. Sessenta annos de vida forense - São Paulo - 1950 - B2-33-15.

57. Simplificaşão processual - Typ. Siqueira - Nagel Cia. - S. Paulo - 1915 - 1 folheto - S5-23-6.

58. Só o devedor com firma inscripta no registro do commercio póde requerer a immissão de seus credores na posse da totalidade dos bens presentes - Tribunal de Justiça de S. Paulo - Agravo - Amparo - (memorial) - Typ. da Companhia Industrial - São Paulo - 1895 - 1 folheto - S5-23-21.

59. Sugestões apresentadas ao ante-projeto do Codigo do Processo Civil e Commercial - Imprensa Nacional - 1936 - 1 volume - P7-10-15.

60. Tentativa de Morte - Tribunal de Justiça de São Paulo Recurso crime - Ribeirão Preto - (memorial) - Typ. do "Reporter" - Ribeirão Preto - 1898 - 1 folheto - S5-23-20.

61. Tentativa de morte - Tribunal de Justiça de São Paulo Recurso crime - Ribeirão Preto - (memorial) - Typ. do "Reporter" - Rib. Preto - 1898 - 1 folh. - S5-23-20.

62. Theses que perante a Congregação de Lentes da Fac. de Direito Propõe-se a defender - Typ. Jorge Seckler - São Paulo $1882-1$ vol. - S3-23-24.

63. Trabalhos Forenses - São Paulo, diversos editores - 1912 B3-13-2.

\section{Direito Civil}

64. Ação de enriquecimento - in Rev. dos Tribunaes - São Paulo - 1919 - vol. 30 - pagina 3 - N5-17-30.

65. Aposentação đos advogados - in Justiça - R. G. do Sul 1937 - vol. 10 - pag. 554 - G1-15-10.

66. Apontamentos sobre a Ord. L. 4 T. 47 pr. - Comunhão de bens - Regimen dotal obrigatorio - in Rev. da Fac. de Direito - São Paulo - 1907 - vol. 16. - pag. 83 - S.C. $34(81.41)(05)-1907$ - v. 16.

67. Aplicą̧ão do Codigo Civil - in Revista Juridica - 1917 vol. 4 - pag. 43 - R12-22-7.

68. O Artigo 550 do codigo civil - in Revista dos Tribunaes São Paulo - 1922 - volume 7 - pagina 89 - N5-16-7.

69. Casamentos em Consulados - in Revista da Fac. de Direito - S. Paulo - 1934 - vol. 30 - pág. 213.

70. O Codigo Civil e os comentadores - "Homestead" - Qualquer pessoa solteira póde, por escrito particular, obrigar-se a vender um imovel embóra só por escritura publica tenha existencia o contrato de venda de imoveis - in Revista dos Tribunaes São Paulo - 1918 - vol. 25 - pag. 174 - N5-17-25. 
71. Compra e Venda - Por Mandatario - Escritura - Instrumento particular - (parecer) in Revista dos Tribunaes - São Paulo - 1918 - vol. 25 - pag. 274 - N5-17-25.

72. Contrato de compra e venda - o instrumento publico vale como escrito particular quando assinado pela parte - Mandato geral "cum libera administratione" - confere poderes para alienar bens de raiz, quando seja de conveniencia do mandante - Prescrição acquisitiva - (parecer) - in Razões da Apelação Civel n. 11.150 - São Paulo - 1921 - 1 folheto S3-23-6.

73. O Curso de Doutorado - in Rev. da Fac. de Direito - S. Paulo - 1934 - vol. 30 - pagina 175.

74. O dano moral, sua indenização - in Revista dos Tribunais - S. Paulo 1925 - vol. 55 - pagina 3 - N5-16-20.

75. Das colações - in Revista dos Tribunaes - S. Paulo 1929 - vol. 70 - pag. 263 - N5-15-5.

76. Das obrigações em materia comercial - in Rev. dos Tribunaes - São Paulo - 1925 - volume 54 - pagina 3 - N5-16-19.

77. Deposito ou consignação - in Revista da Fac. de Direito S. Paulo - 1912 - vol. 20 - pagina 99.

78. Direito Romano - Diferença entre obrigaçóes correaes e simplesmente solidarias - in Revista da Fac. de Direito - S. Paulo - 1906 - vol. 14 - pag. 2-25.

79. Doação - Interpretação - Compra e Venda posterior Excesso - Nulidade - Ações competentes - (Parecer) - in Revista dos Tribunaes - São Paulo - 1917 - volume 22 pagina 257 - N5-17-22.

80. O Doutorado - in Rev. da Fac. de Direito - S. Paulo - 1935 - vol. 31 - pag. 298.

81. E a epilepsia motivo para a nullidade do casamento? - (Parecer) - in Revista de Direito - Rio de Janeiro - 1914 volume 32 - pagina 47 - N1-16-6.

82. Efeitos do registro do contrato de sociedade em comanditain Revista da Fac. de Direito - S. Paulo - 1935 - parecer vol. 31 - pag. 271.

83. Extingue-se a ação de desquite pela morte de um dos conjuges? - In Revista da Fac. de Direito - S. Paulo - 1935 vol. 31 - pag. 264.

84. Fecundação artificial - Semen de um cadaver - Paternidade (Parecer) - in Revista de Direito - Rio de Janeiro - 1918 - vol. 48 - pag. 294.

85. Historia externa do direito romano - in Rev. da Fac. de Direito - S. Paulo - 1906 - vol. 14 - pag. 103. 
86. Indicação - Ainda sobre o codigo do processo em elaboração — in Revista da Faculdade de Direito - S. Paulo - 1935 vol. 31 - pag. 519.

87. Indices das leis mais notaveis do Estado de São Paulo - in Revista da Fac. de Direito - S. Paulo 1912 - vol. 20 pag. 203.

88. Literatura juridica - Direito Civil — Segunda edição da obra do Dr. Eduardo Espinola "Systema do Direito Civil Brasileiro" — in Revista dos Tribunaes - São Paulo — 1917 - volume 24 - pagina 237 - N5-17-24.

89. Louvação em demarcações e divisões - in Revista dos Tribunaes - São Paulo - 1921 - volume 3 - pagina 4445 N5-16-3.

90. Patrio Poder - in Revista da Fac. de Direito - S. Paulo 1910 - vol. 18 - pag. 67.

91. Posição social da mulher na antiga Roma - (Preleção no Curso de Direito Romano) - in Rev. da Fac. de Direito S.Paulo - 1941 - vol. 36 - pagina 195.

92. A prescripção das ações "ex empto, redhobitoria" e "quanti minoris" no direito patrio - in Rev. dos Tribunaes - S. Paulo - 1912 - vol. 12 - N5-17-2.

93. Primeira lição sobre os direitos da familia - in Revista àa Faculdade de Direito — São Paulo - 1908 - vol. 16 - pág. 145.

94. Regimen dotal - in Rev. da Fac. de Direito - São Paulo 1907 - vol. 15 - pag. 49.

95. Prova de filiação legitima - in Rev. dos Tribunaes - S. Paulo - 1918 - vol. 26 - pagina 133 - N5-17-26.

96. Segredo Profissional - in Revista dos Tribunaes - S. Paulo - 1928 - volume 66 - pagina 3 - N5-15-1.

97 Solenidades do casamento na antiga Roma - (preleções no curso de direito romano) - in Rev. da Faculdade de Direito - São Paulo - 1941 - vol. 36 - pagina 201-205.

98. Successão de filhos adulterinos - in Revista da Fac. de Direito - S. Paulo - 1934 - (parecer) - vol. 30 - pagina 281-282.

99. Sobre successões - in O Direito - Rio de Janeiro - 1908 volume 106 - pag. 12 e 30 - P15-23-7.

100. Successão "Ab intestato" - Netos que concorrem á herança com tios vivos - (Pareceres) - in Rev. Forense - B. Horizonte - 1931 - volume 57 - pag. 11 - M3-14-25.

101. Successão "ab intestato" - Descendentes de herdeiros premortos em concurrencia com tios vivos - Como deve ser feita a 
partilha entre aquelles - Se "per capita" ou por estirpe (Parecer) - in Revista dos Tribunaes - São Paulo - 1931 vol. 80 - pagina 312 .

102. Testamento cerrado - Quem póde ser testemunha - in Rev. dos Tribunaes - São Paulo, - volume 21 - pagina 65 N5-17-21.

\section{Direito Comercial}

103. Arrematação de bens da massa falida pelo ex-sindico ou liquidatario - (Parecer) - in Revista de Jurisprudencia Brasileira - Rio de Janeiro - 1940 - volume 48 - pag. 15.

104. O artigo 206 do nosso codigo comercial - Riscos da coisa vendida em casos de mercadorias importadas do extrangeiro, nos quaes se complica, quasi sempre a especie com a clausula cif ou caf - in Revista dos Tribunaes - São Paulo - 1922 - volume 8 - pagina 431 - N5-16-8.

105. Cessão de clientela - (parecer) - in Ação Ordinaria - São Paulo - 1911 - paginas 3 a 180 - S3-23-5.

106. Cheque - Incorre em penas de estelionato o individuo que, depois de o emitir retira das mãos do sacado a provisão de fundos? - in Revista dos Tribunaes - São Paulo, - 1933 volume 86 - pag. 220 .

107. Concordata - Credores particulares do socio - Effeito Obriga a concordata feita por uma sociedade, aos credores particulares de um socio de responsabilidade illimitada? (parecer) - in Revista dos Tribunaes - São Paulo - 1918 volume 25 - pagina 275 - N5-17-25.

108. Contratação de patente de invenção (Parecer) - in Revista de Jurisprudencia Brasileira - Rio de Janeiro - 1941 volume 51 - pag. 256.

109. Da administração das sociedades anonimas - in Revista da Fac. de Direito - São Pauło - 1912 - vol. 20 - pag. 217.

110. Das assembléias de accionistas - in Rev. da Fac. de Direito - S. Paulo - 1912 - vol. 20 - pag. 179.

111. Decreto de 31 de dezembro $n$. 2.044 - de 1908 annotado. São Paulo - Escolas Profissionais Salesianas - 1914-1915 P13-16-24.

112. Defesa na ação cambial - in Rev. da Faculdade de Direito - São Paulo - 1911 - vol. 19 - pag. 189.

113. Defesa na ação cambial - parte pratica - in Rev. da Faculdade de Direito - São Paulo - 1912 - vol. 20 - pag. 9-29. 
114. Fallencia - Fraudulenta - Quitação dos credores - Efeito em relação ao processo - Deve prosseguir a ação penal contra - negociante acusado de falencia fraudulenta, que obteve, quitação de seus credores? - (parecer) - in Revista dos Tribunaes - São Paulo - 1918 - vol. 25 - pag. 277.

115. Falencias - A obra do Dr. Carvalho de Mendonç - in Revista dos Tribunaes - São Paulo - 1918 - volume 26 pag. 17 - N5-17-26.

116. Habitos mercantis máus e perigosos - in Revista do Comercio e Industria - São Paulo - 1919 - volume 5 - pagina 67 Q15-20-67.

117. Justiça cara - A urgencia de uma lei que torne facultativa a đistribuição dos processos em São Paulo - in Revista da Fac. de Direito de São Paulo - 1936 - volume 32 - pag. 501.

118. Letra em branco, ou incompleta - in Rev. dos Tribunaes São Paulo - 1921 - volume 4 - pagina 50 - N5-16-14.

119. A letra de cambio actual - in Revista da Fac. de Direito S. Paulo - 1911 - vol. 19 - pagina 135.

120. Letras de favor - Fallencia - Inđenização - in Revista de Comercio e Industria - São Paulo - 1919 - volume 5 pagina 177 - Q15-20-16.

121. Letras de favor - Fallencia - Indenização - (parecer) in Revista Forense - Belo Horizonte - 1919 - volume 32 pagina 239 - M2-14-31.

122. Logar de pagamento das letras de cambio - (parecer) - in Revista dos Tribunaes - São Paulo, - 1927 - volume 63 pagina 647 - N5-16-28.

123. Marcas de fabrica e de comercio - in Diversos Artigos "Diario Nacional" - São Paulo - 22-1-31 - pag. 1 - P7-10-16.

124. Multiplicação da letra de cambio - in Rev. da Faculdade de Direito - S. Paulo - 1911 - vol. 19 - pag. 111.

125. Natureza mercantil da letra de cambio - in Revista do Comercio e Industria - São Paulo - 1918 - volume 4 - pag. 349 - Q15-20-15.

126. Parecer sobre o projecto do Dr. Inglez de Souza - in Revista da Fac. de Direito - São Paulo - 1913 - vol. 21 - pag. 43

127. Prefacio aos "Elementos de Direito Comercial" de Cesar Tripoli - E. G. da Revista dos Tribunaes - São Paulo - 1932 2 vol. - pag. 5 - N14-13-26.

128. Da Responsabilidade dos administradores das sociedades anonimas - in Revista da Faculdade de Direito - S. Paulo 1913 - vol. 21 - pag. $11-42$ - S.C. 
129. Sociedade Comercial - Comandita simples - Contrato social archivado no registo de titulos da Comarca - Operações realisadas pelo comanditario - Sua responsabilidade com a falencia da sociedade - (Parecer) - in Rev. dos Tribunaes São Paulo - 1935 - vol. 194 - pag. 36 - N5-14-5.

130. Simplificação processual — in Rev. da Fac. de Direito de S. Paulo - 1912 - vol. 20 - pag. 115-122.

131. Titulos de Favor - in Rev. da Fac. de Direito - S. Paulo - 1911 - vol. 19 - pag. 221-223 - S.C.

132. Transferencia de ações em sociedade anonima - "Mora solvendi" e "mora Accipiendi" - (Parecer) - in Embargos numero 7.211 - S. Paulo - 1914 - pag. 147 - N11-20-8.

133. Tratado de direito comercial brasileiro do Dr. Carvalho de Mendonça - in Revista dos Tribunaes — S. Paulo - 1926 vol. 60 - pag. 3 - N5-16-25.

134. O tratado de direito comercial de Carvalho de Mendonça5 volumes - in Revista dos Tribunaes — S. Paulo - 1920 vol. 35 - pag. 372 - N5-17-35.

\section{Direito Penal}

135. Da Tentativa - in Rev. da Fac. de Direito - S. Paulo 1910 - vol. 18 - pag. $9-25$ - S.C.

136. Hypnotismo e responsabilidade juridica - in Rev. dos Tribunaes - S. Paulo - 1920 - vol. 37 - pag. 177 - N5-17-37.

137. Inquirição e reinquirição de testemunhas - in Revista dos Tribunaes - S. Paulo - 1922 - vol. 7 - pag. 283.

138. A luta contra o delito - in Rev. da Fac. de Direito - S. Paulo - 1906 - vol. 14 - pag. 67 - S.C.

139. Passionalismo - in Revista dos Tribunaes - S. Paulo 1941 - vol. 130 - pag. 451 - N5-13-6.

140. O poder disciplinar da Ordem dos Advogados e o Direito penal - in Boletim Oficial da Seç̧ão de São Paulo da Ordem dos Advogados do Brasil - S. Paulo - 1935 - Pareceres - vol. 2 numero 4 - pag. 35 - L1-11-2.

141. Queixa por procurador - (Pareceres) - in Revista Forense - Belo Horizonte - 1910 - numero 14 - pag. 389 - M2-14-12.

142. Violação de patente - Concessionario extrangeiro com proprocurador no país - Ação penal - Formalidade preliminar - in Rev. de Direito - Rio de Janeiro - 1910 - volume 18 - pag. 235 - N1-17-18. 


\section{Direito Público}

143. Arte de governar - in Rev. da Fac. de Direito - São Paulo - 1943-44 - vol. 39 - pag. 65 a 68 - S.C.

144. A Capital no Planalto de Goyaz - in Rev. da Fac. de Direito - S. Paulo - 1914 a 1925 - vol. 22 - pag. 202-212 - S.C.

145. Concessão de serviços publicos - Tributação por pessoa juridica de direito publico diversa da concedente ou por ella propria - Inadmissibilidade - Aplicação do art. 17 - n. 10 - da Constituição Federal - (Parecer) - in Revista dos Tribunaes - S. Paulo - 1936 - volume 100 - pag. 25 - N5-14-11.

146. Democracia e Liberalismo - in Rev. da Fac. de Direito - S. Paulo - 1929 - vol. 25 - pag. 253-358 - S.C.

147. São democraticas as convenções? - in Diversos artigos - "Jornal do Comercio" - S. Paulo - 19 de julho de 1921 - pag. 17, 18 e 19 - P7-10-16.

148. Direito Publico - Regulamentação - in Rev. da Fac. de Direito - S. Paulo - vols. 18 e 19 - S.C. - 1910 e 1911.

149. Estado de Sítio e eleições - (Pareceres) - in Revista de Direito - Rio de Janeiro - 1918 - vol. 49 - pag. 251 N1-16-23.

150. Estrada de Ferro - Multa do governo - Interpretação do decreto - in Revista dos Tribunaes - S. Paulo - 1918 vol. 26 - pag. 120 - N5-17-26.

151. Imposto sobre capital das sociedades anonimas - Exploração de serviços publicos pagamento dos direitos aduaneiros Inexistência dos lucros - Concessão feita pela União - Isenção - Aplicação do art. $1 \S 3 .^{\circ}$ n. VI da lei n. 920 de 1904 - N5-14-11.

152. Pagamento indevido - Imposto - "Conditio indebiti" - Repetição - Requisitos para a sua procedencia - (Parecer) - in Revista dos Tribunaes - S. Paulo - 1936 - volume 100 pag. 25 - N5-14-11.

153. O Poder Judiciario em face do Governo Provisorio - in Revista da Fac. de Direito - São Paulo — 1934 — vol. 30 - pag. 9-11 - S.C.

154. Reforma Constitucional - in Revista da Rac. de DireitoSão Paulo - 1935 - vol. 31 - pag. 181-219 - S.C.

155. Taxa de Viação urbana - Exigencias aos contribuintes do imposto de calçamento - Inadmissibilidade - Interpretação do artigo 9 § unico do acto municipal numero 2.791 da 
Prefeitura de S. Paulo - (Parecer) - in Revista dos Tribunaes - São Paulo - 1935 - volume 96 - pagina 50 - N5-14-7.

156. Uso ilegal do titulo de doutor pelos bachareis em direito - in Revista dos Tribunaes — São Paulo - 1934 - volume 90 - pag. 441 - N5-14-1.

\section{Direito Internacional}

157. O desarmamento e a paz universal - in Revista da Faculdade de Direito - São Paulo - 1934 - vol. 30 - pag. 439 - S.C.

\section{Processo}

158. Abolição da taxa judiciaria e redução de outras taxas - Restabelecimento das custas aos advogados - Distribuição livre ou facultativa - in Boletim Official da Secção de São Paulo - da Ordem dos Advogados do Brasil - São Paulo - 1936 abril ano III - numero 8 - pagina 25 - L1-11-3.

159. Advogados em inventários e partilhas - Necessidade de sua intervenção - Direito das successões - Dificuldades que oferece - in Revista dos Tribunaes - São Paulo - 1935 volume 95 - pag. 303 - N5-14-8.

160. Concurso de credores - in Revista de Direito - Rio de Janeiro - 1910 - vol. 16 - pagina 519 - N1-17-16.

161. Corre por conta do agravado a copia das peças que pedir in Revista dos Tribunaes - São Paulo - 1918 - volume 21 - pagina 323 - N5-17-29.

162. Cumúlações de ações de demarcação - de turbação e de esbulho - (parecer) - in Revista de Direito - Rio de Janeiro - 1914 - volume 31 - pag 456 - N1-16-5.

163. Entrega de autos - in Revista dos Tribunaes - São Paulo 1920 - volume 37 - pagina 427 - N5-17-37.

164. O Escrivão — in Rev. dos Tribunaes - São Paulo - 1921 pag. 284 - N5-16-2.

165. Effeitos da apelação - in Revista dos Tribunaes — São Paulo - 1918 - volume 28 - pagina 11 - N5-17-28.

166. Executivos hypotecarios - in Rev. dos Tribunaes — São Paulo - 1917 - vol. 24 - pag. 161 - N5-17-24.

167. o Fôro no Estado Novo - in Rev. da Fac. Direito de S. Paulo - 1939 - vol. 35 - pag. 565 - S.C.

168. Pelo Fôro - O relatorio do Exmo Snr. Diretor do Fôro in Diversos Artigos - "Jornal do Comercio" - 9 de fev. de 1926 - pag. 11 e 12 - P7-10-16. 
169. O Juiz é obrigado a cumprir os acordãos do Tribunal in Revista dos Tribunaes - São Paulo - 1920 - vol. 1 pag. 194 - N5-16-1.

170. Juizo Arbitral - in Rev. dos Tribunaes - São Paulo - 1921 - vol. 5 - pag. 95 - N5-16-5.

171. Mandato - Desistencia do feito pelo mandante - Consequencias - (Pareceres) - in Rev. dos Tribunaes - São Paulo 1918 - vol. 26 - pag. 355 - N5-17-26.

172. Pluralidade de autores - Acções - Cumulação - in Rev. de Direito - Rio de Janeiro - 1909 - volume 13 - pag. 474 N1-17-13.

173. Prefacio do "Manual das leis de justiça do Estado de São Paulo" de Joaquim Gonçalves de Oliveira - in Manual de Leis de Justiça — São Paulo - 1927 - pag. 7 - S-16-11-19.

174. Prova testemunhal - Seu valor —Direito das testemunhas in Revista dos Tribunaes - São Paulo - 1929 - vol. 69 - pag. 231 - N5-15-4.

175. Tribunal de Etica Profissional - Cobrança de honorários (Parecer) - in Boletim Oficial da Secção de São Paulo 1941 - abril, maio e junho - anno VIII - numero 28 - pag. 37 - L1-11-9.

176. Usufruto e Fideicomisso - in Revista Juridica - 1917 vol. 6 - pag. 448 - R12-22-9.

177. Voto Secreto - in Rev. dos Tribunaes - São Paulo - 1917 vol. 25 - pag. 3 - N5-17-25.

\section{Diversos}

178. Augusto Comte - A Conferencia do professor Dumas na Faculdade de Direito - in Diversos artigos - pag. 8 e 9 P7-10-16.

179. Congresso médico — Revista Juridica - 1917 - vol. 5 pag. 31 - R12-22-8.

180. O Conselheiro Ruy Barbosa - in Revista da Fac. de Direito - São Paulo - 1914 a 25 - vol. 22 - pag. 241-259 - S.C.

181. Conservação dos recursos naturaes - in Rev. da Fac. de Direito - São Paulo - 1914 a 1925 - vol. 22 - pag. 129 147 - S.C.

182. A crise e a advocacia - in proletariado intelectual — São Paulo - 1935 - pag. 34 - S11-23-23.

183. Defesa Social - in Diversos artigos — "O Estado de São Paulo" - 18-2-1909 - pag. 21 - P7-10-16. 
184. O Consumidor - in Rev. da Fac. de Direito - São Paulo 1934 - vol. 30 - pag. 643 - S.C.

185. A democracia - in Rev. da Fac. de Direito - São Paulo 1935 - vol. 31 - pag. 5-26 - S.C.

186. Os desocupados - in Rev. da Fac. de Direito — São Paulo 1930 - vol. 26 - pag. 131 - S.C.

187 o dever dos moços — in Revista da Fac. de Direito - São Paulo - 1930 - vol. 26 - pag. 155 - S.C.

188. O Direito Romano e o seu methodo - Gazeta Juridica - São Paulo - 1903 - vol. 33 - pagina 3 - R16-23-21.

189. O eclipse do liberalismo - in Rev. da Fac. de Direito de São Paulo - 1903 - vol. 33 - pagina 3 - R16-23-21.

190. Estevam de Almeida - in Revista da Fac. de Direito - São Paulo - 1947 - volume XLII - pag. 160 - S.C.

191. "Filosofia do Direito" do professor João Arruda - Resposta ao Dr. Plinio Barretto - in Rev. da Fac. de Direito - São Paulo - 1942 - vol. 38 - pag. 340 - S.C.

192. Indigencia e socorros - in Revista da Fac. de Direito São Paulo - 1926 - vol. 23 - pag. 253 - S.C.

193. Jurisconsultos Brasileiros - in Revista Juridica - vol. 3 1916 - pag. 193 - R12-22-6.

194. Luxo governamental e miséria popular - in Diversos artigos "Jornal do Comercio" edição de São Paulo - 5 de março de 1922 - pag. 9 e 10 - P7-10-16.

195. Os menores e os cinemas - in Diversos artigos - pag. $19 \mathrm{e}$ 20 - P7-10-16.

196. A missão dos escóes - in Rev. da Fac. de Direito - São Paulo - 1930 - vol. 25 - pagina 41 e 45 - S.C.

197 Novas directrizes da educação - in Revista da Faculdade de Direito — São Paulo - maio agosto 1938 - volume XXXIV - fasciculo II - pag. 170 - S.C.

198. Opulencia e Miseria - in Rev. da Faculdade de Direito São Paulo - 1926 - vol. 23 - pag. 247 - S.C.

199. Parecer sobre trabalhos de candidatos ao exercico do magistério superior na Faculdade de Direito de São Paulo - in Rev. da Fac. de Direito - S. Paulo - 1911 - vol. 19 - pag. 187 - S.C.

200. Pela dignidade e segurança da patria - in Rev. da Fac. de Direito - São Paulo - 1939 - volume 35 - pag. 411 - S.C.

201. Pelos Lazaros - in Diversos artigos - pag. 2 - P7-10-16. 
202. o povo tem o governo que merece - in Diversos artigos "Jornal do Comercio" — São Paulo — 8 de fev. de 1922 pag. 3 - P7-10-16.

203. Problemas Sociaes - in Rev. da Faculdade de Direito - São Paulo - 1914 - vol. 22 - pag. 149 - S.C.

204. Professores de direito - Outróra e hoje - in Revista da Faculdade de Direito - São Paulo - 1937 - vol. 33 - pag. 309 - S.C.

205. Profissões liberaes - in Rev da Fac. de Direito - São Paulo - 1929 - vol. 25 - pag. 335 - S.C.

206. Proletariado intelectual - in Revista da Fac. de Direito de São Paulo - 1935 - memorias apresentadas ao Conselho da Ordem dos Advogados - vol. 31 - pag. 220 - S.C.

207. Proventos da profissão - in Revista dos Tribunaes - São Paulo - 1920 - volume I — pag. 83 - N5-16-1.

208. Psychologia judiciaria - in Revista da Faculdade de Direito - São Paulo - 1931 - vol. 27 - pag. 163 - S.C.

209. Reforma do ensino superior - in Rev. da Fac. de Direito São Paulo - 1929 - vol. 25 - pag. 549 - S.C.

210. Relendo Victor Hugo - in Diversos artigos - "Diário Popular" - 15-7-1927 - pag. 13 - P7-10-16.

211. Sepulturas perpetuas - in Rev. da Fac. de Direito - São Paulo - 1926 - vol. 23 - pag. 269 - S.C.

212. Sugestões apresentadas pelo Conselho da Ordem dos Advogados do Brasil, Seção de São Paulo ao ante-projeto do Codigo de Processo Civil e Comercial - in Primeiro Congresso Nacional de Direito Judiciario - Rio de Janeiro - 1942 - volume 2 - anéxos - I parte - paginas 119 e 122 - S12-12-20.

213. Trabalho e goso - in Diversos artigos - in "Jornal do Comercio" 12 de setembro de 1921 - pag. 16, 16 e 17 - P7-10-16.

214. União Sul-Americana - in Revista do Direito - Rio de Janeiro 1924 - vol. 71 - pag. 430 - N1-15-19.

215. Uso ilegal do titulo de doutor - Declaração de voto - "Fôlha da Manhã" - São Paulo - 5-7-1934 — livro de recórtes de jornais - pag. 89 - U1-20-7. 